\title{
O ACOLHIMENTO, A CURA E OS VULTOS: REFLEXÕES SOBRE A RELIGIÃO E A MILITÂNCIA NEGRA-NORTE-AMERICANA DO SUL DOS ESTADOS UNIDOS ${ }^{1}$
}

\author{
Rosemarie Freeney Harding ${ }^{2}$ \\ Rachel Elizabeth Harding ${ }^{3}$
}

\begin{abstract}
Resumo: Este texto, uma colaboração entre Rachel e sua falecida mãe, Rosemarie, reconta, por meio de memórias da vida de Rosemarie enquanto militante no movimento negro dos anos 60 e pela história oral da família Freeney-Harding, a experiência dos negros norte-americanos que migraram do sul do país para cidades do norte do país nas primeiras décadas do século vinte. O texto examina tradições de acolhimento, cura, e uma espiritualidade mística afro-indígena do sul dos Estados Unidos como recursos para militância social e racial na comunidade negra norte americana. O texto está escrita na voz de Rosemarie.

Palavras-chave: Ativismo. Negros Sul-americanos. Espiritualidade. Misticismo. Família.
\end{abstract}

\section{HOSPITALITY, HEALING AND HAINTS: AFRICAN AMERICAN INDIGENOUS RELIGION AND ACTIVISM}

\begin{abstract}
This text, a collaboration between Rachel and her late mother, Rosemarie, draws from stories of Rosemarie's life as an organizer in the southern freedom movement of the 1960s, and from the Freeney-Harding family's oral history, to explore the experience of African Americans who migrated to northern cities in the early decades of the twentieth century. The essay looks particularly at traditions of hospitality, healing, Southern mystic spirituality and grassroots activism as resources for social justice organizing in Black American life. The text is written in Rosemarie's voice.

Keywords: Activism. Southern Blacks. Spirituality. Mysticism. Family.
\end{abstract}

1 Tradução de:

Jonathas Martins Nunes - Graduando em Letras Língua Inglesa pela Universidade do Estado da Bahia (UNEB/Campus IV), Bolsista de Iniciação Científica (FAPESB), pesquisador do grupo Desleituras em série: da tradução como transcriação, adaptação, refração, diáspora (UNEB).

José Carlos Felix — Professor adjunto da Universidade do Estado da Bahia (UNEB/Campus IV) e professor permanente do Programa de Pós-Graduação em Crítica Cultural. Pesquisador pelo grupo Pós-Teoria, UNEB/PÓS-CRÍTICA. Tem trabalhos publicados na área de literatura, cinema e crítica cultural no Brasil e no exterior. E-mail: jcfelixjuranda@yahoo.com.br.

Rosemarie Freeney Harding (1930-2004) foi uma ativista, educadora e conselheira que lutou no Movimento dos direitos civis dos negros nos Estados Unidos e por outras causas de paz e justiça, em parceria com seu marido, Vincent Harding. Freeney Harding co-fundou a Casa Menonita em Atlanta, Georgia, e o projeto Veterans of Hope Project em Denver, Colorado. Obteve um MSW (Mestrado em Serviço Social) pela Universidade de Denver (UCDenver) e mestrado em História pela Goddard College.

3

Professora Assistente de Tradições Espirituais Indígenas no Departamento de Estudos Étnicos da Universidade do Colorado em Denver (UCDenver). É PhD em História pela Universidade do Colorado, Boulder. Ela é autora de A Refuge in Thunder: Candomblé and Alternative Spaces of Blackness. E-mail: Rachel.Harding@ucdenver.edu. 
Minha família é uma família sulista. Embora tenhamos vivido em Chicago por cinco gerações, somos ainda, em muitos aspectos, profundamente influenciados pelos rituais e tradições que viajaram conosco no trem, o Seminole Limited, vindo de Macon, Geórgia, Estados Unidos. Meus pais, avós, tias, tios, e a maioria dos meus irmãos e irmãs nasceram em cidades pequenas da Geórgia - Leesburg, Poulan, Albany, Macon. Entre as décadas de 1910 e 1920, eles começaram a se deslocar para o norte. Primeiro, as irmãs de minha mãe e seus maridos, meu pai e seu irmão. Em seguida, outros parentes - esposas, filhos, pais. Todos eles eram atraídos pelos empregos nas usinas siderúrgicas e pátios ferroviários, escapando dos pesadelos de linchamentos e humilhações e constante agressões sofridas na vida cotidiana do Sul e em meio às guerras. De certa forma, meus familiares foram arrancando de suas raízes, movendose para Detroit, Nova York e Chicago. De outra forma, iam apenas esticando as raízes, mudando um pouco de seus contornos, mas firmando-se à profunda nutrição que lá ascendia.

Os valores da religião e da cultura negra que me influenciaram na juventude em Chicago foram fundamentados em tradições de hospitalidade; práticas de cura; histórias de fantasmas e espíritos; tudo isso em uma comunidade acolhedora e inclusiva. Todos estes aspectos impactaram profundamente no meu modo de viver e agir no mundo. Entre os aspectos, talvez, a hospitalidade tenha sido um modelo central para o significado de militância na minha vida. Antes dos meus filhos nascerem, eu era o que algumas pessoas chamariam de militante trabalhando em campanhas políticas; organização de escolas alternativas; treinamentos, mobilizações e práticas de reconciliação dentro do movimento de libertação negra (também conhecida como a luta pelos direitos civis dos negros,) o movimento das mulheres e do movimento da paz e da justiça. Trabalhei com algumas pessoas magníficas, profundamente comprometidos com um entendimento de mudança social bem engajada com espiritualidade e compaixão. Pessoas como: Bob Moses, Anne Braden, Ella Baker, Septima Clark, Prathia Hall, Gwendolyn Zoharah Simmons, Clarence Jordan, Bernice Johnson-Reagon, Marion e Slater King, Jimmy e Grace Lee Boggs, Julia Esquivel, Ndugu T'Ofori Atta, Staughton e Alice Lynd. Aprendi muito com essas mulheres e homens maravilhosos, assim como muitos outros iguais a eles. Mas quando penso sobre o meu próprio trabalho no movimento negro e suas inspirações mais íntimas, sempre volto para o exemplo da minha família - especialmente minha mãe, Ella Lee ("Mama Freeney”) e minha bisavó Mariah ("Vovó Rye”), e a profunda espiritualidade mística e a intensa hospitalidade que elas cultivavam e passavam para seus descendentes.

Algumas pessoas que se lembram das histórias dizem que a vovó Rye nasceu na África. Ela nasceu provavelmente por volta de 1827 e pode ter vindo para os Estados Unidos ainda 
quando criança, porque morreu em 1934 na idade de 107. Ela era uma escrava na Virgínia e na Flórida, e trabalhou ao longo da costa leste em um navio, onde cozinhava para o capitão e toda tripulação. Na época em que minha avó, mãe Liza, nasceu, faltavam apenas três anos para a abolição da escravidão e Mariah e seus filhos viviam na Geórgia.

Em meus esforços a fim de delinear e compreender os valores religiosos e espirituais que chegaram até a minha família pela Vovó Rye, aprendi com o trabalho do historiador de religiões, Charles Long e do filósofo-dramaturgo George Bass. ${ }^{4}$ O significado da religião para o povo negro, insistem Long e Bass, está no coração da nossa história, no nosso trauma e nossa esperança. É o que nos faz nativos deste lugar, à modernidade. Assim como Long coloca, a religião negra é o caminho pelo qual temos nos orientado - ao longo dos séculos nas Américas, e mesmo antes de nossa chegada nestas costas - para "expurgar o sentido" da vida em meio ao tremendo sofrimento e dor. A religião, nesse sentido, não é simplesmente uma doutrina de fé ou os métodos e práticas da igreja, mas sim, todas as maneiras pela qual nos lembramos de quem realmente somos, ao invés de que dizem de nos os poderes temporais. A religião é como nós nos situamos, como entendemos a nós mesmos, em um determinado lugar e tempo perante a Realidade Suprema, perante a Deus.

Nessas circunstâncias, a religião negra não está somente na música, na teatralidade, na comunhão e na interpretação de textos dentro dos muros e paredes de um "templo religioso"; ela está também nas escolhas que o negro faz em relação à chamada cultura secular. A religião negra é tanto Otis Redding e D'Angelo quanto Mahalia Jackson e Mary Mary; é tanto hip hop quanto o derramar do espirito santo; é tanto o Hoodoo quanto a dar passe com as mãos. É como discernimos o sentido e a alegria de nossa experiência humana. Tendo em mente toda essa discussão, irei adentrar as tradições culturais e espirituais da minha família para refletir sobre os significados e manifestações de uma orientação ao processo de "being" tipicamente negro americano sulista.

Esta orientação não é única de minha família. Eu cresci com muitas famílias negras do Mississippi, do Alabama e da Geórgia - e vivi por muitos anos na Geórgia enquanto adulta.

4 Ver Charles H. Long, "Perspectives for the Study of African American Religion in the United States," In: Fulop and Raboteau, African American Religion: Interpretive Essays in History and Culture (New York: Routledge, 1997) e Charles H. Long, Significations: Signs, Symbols and Images in the Interpretation of Religion (Philadelphia: Fortress, 1986). Além disso, as palestras de George H. Bass em seus cursos de Estudos afro-americanos na Brown University, e conversas que Rachel teve com ele quando era seu professor, 1983-1990. 
Estou nitidamente ciente da difusão da orientação que eu descrevo. Mesmo agora, no final da década de 1990, existem maneiras de ver e senti-la em comunidades afro-americanas em todo o país. Esta orientação é parte de como chegamos até aqui e como nós seguimos em frente. E foi neste solo que o Movimento levantou-se e ofereceu novos frutos para a nação.

\section{O acolhimento}

Minha mãe e minhas tias mantinham prontos um jarro de chá gelado ou limonada na geladeira e um prato com biscoitos, um bolo recém feito, ou pãezinhos com geleia caseira em cima do balcão. Para qualquer um que viesse nos visitar era oferecido algo refrescante para beber (ao menos que fosse inverno, é claro, quando lhes ofereciam café ou chá) e algo saboroso para comer. Nos anos em que eu crescia, as pessoas visitavam umas às outras, mais regularmente do que fazem agora, e nossa casa parecia ser um destino muito popular para os vizinhos e parentes. Isto foi em parte devido ao fato de que tínhamos uma grande família e meus irmãos e irmãs mais velhos eram todos extrovertidos, com muitos amigos. E também, porque meus pais tornavam a casa bastante acolhedora. Às vezes, parecia "demasiadamente" acolhedora - todos os tipos de pessoas eram bem-vindas, não só parentes e amigos da vizinhança, mas vendedores ambulantes e pregadores, apostadores profissionais e organizadores sindicais, gatunos, prostitutas e pessoas que provavelmente são conhecidas hoje como sem-teto. Minha mãe adorava pessoas ditas "ruins" - isto é, pessoas das quais a sociedade julgava com índole duvidosa. Ela não julgava ninguém e nos ensinou a respeitar, ouvir e aprender com todos. Minha mãe colocava seus belíssimos pratos de porcelana e fatias do seu bolo caseiro de manteiga para todos eles - especialmente para aqueles que às vezes se pareciam os mais maltrapidos. Como se soubesse que estas pessoas precisavam de atenção e acolhimento. Pensando bem, minha mãe gostava mesmo era da conversa com aquelas pessoas e sua sabedoria.

Eu me lembro que havia um vendedor de livros, um imigrante da Europa, que costumava visitar minha mamãe de vez em quando. Os dois costumavam se sentar na sala de jantar com os melhores pratos da mamãe e falar por horas sobre os acontecimentos do mundo e o mundo dos livros. Nem sempre o homem estava muito limpo e, por vezes, especialmente no inverno, quando o aquecimento estava alto em nossa casa, podíamos sentir o cheiro do mofo de suas roupas velhas e rasgadas, e o suor forte e azedo de seu corpo. Ele também falava embolado, e como éramos crianças, ficávamos tentados a rir - tanto do desconforto quanto de 
qualquer outra coisa. Mas se deixássemos sair o mais ínfimo dos risos, minha mãe teria rapidamente nos lançado um olhar de reprovação, nos fazendo abandonar a tentação e manter os nossos rostos sérios.

Como eu disse, tenho uma família numerosa. Minha mãe deu à luz a dezesseis filhos, mas apenas nove chegaram até a idade adulta. É nós, os nove, éramos apenas um contingente de um grande círculo de primos, tios e tias, alguns dos quais eu não sabia distinguir quem era realmente parente de sangue, algo que só fora acontecer muito mais tarde, quando eu já era adulta e estava criando meus próprios filhos. Até 1976, quando meu pai morreu e minha mãe vendeu a casa, havia sempre alguém morando com meus pais, na casa da família, na rua Wentworth Sul, 4160 - um filho, um sobrinho ou sobrinha, e depois netos e sobrinhos-netos. Meus pais sempre abrigavam a todos e qualquer um de nós poderia sempre voltar para casa. Hospitalidade era a base da espiritualidade de minha família, assim como para muitos negros do Sul. Os esforços que meus pais fizeram para serem prestativos, receptivos e, ao mesmo tempo, não cair na tentação de julgar precipitadamente aqueles vistos como marginais pela sociedade, serviram como exemplos importantes para os seus filhos e netos enquanto crescíamos.

Uma das minhas primeiras tarefas como uma jovem militante do Movimento Negro foi o desenvolvimento de um projeto de serviço social, e centro comunitário interracial chamado Casa Menonita em Atlanta, Geórgia, no início dos anos 1960. O Comitê Central Menonita ( $\mathrm{MCC}$ - a subdivisão de serviços sociais da igreja Menonita) patrocinava a mim e a Vincent para sermos missionários em tempo integral e participantes do Movimento Negro. Além do nosso trabalho de condução dos voluntários com várias organizações do movimento, a formação de jovens militantes e a coordenação de esforços iniciais para o diálogo e reconciliação inter-racial, a Casa Menonita se tornou um importante local de refúgio para muitos que estavam lutando e se sacrificando para transformar o Sul em particular e a nação Norte-americana em geral. Às vezes militantes costumavam nos ligar da estação rodoviária e Vincent ia até lá e dava-lhes uma carona até a Casa Menonita, onde eles ficavam por alguns dias ou semanas, porque precisavam de um lugar para descansar um pouco. Por causa do exemplo da minha mãe, eu compreendi perfeitamente o quão importante era ter espaços de refúgio no meio da luta. Espaços de alegria e risos, boa comida e palavras gentis. Na verdade, este tipo de cuidado afetuoso é uma força transformadora em si. Como escreveu o romancista de Cabo Bretão, Alistair MacLeod: "Somos todos melhores quando somos amados". 


\section{Cura}

Atualmente, a maioria das pessoas na família que se lembrava de Mariah Grant já se foram. Mas as histórias que sobreviveram sobre minha bisavó incluem recordações de seu trabalho de cura e sua conexão com formas africanas de perceber e pertencer ao mundo. Vovó Rye era uma curandeira e fitoterapeuta. Ela coletava plantas e flores, raízes e folhas nos campos e florestas ao redor de sua casa em Leesburg, e com isto fazia medicamentos para tratar os membros de sua família e outros que iam até ela buscando conselhos e opiniões.

Mãe Liza, uma das filhas de Mariah, continuou a tradição de cura de sua mãe de outra maneira. No condado de Lee, Geórgia, Liza Harris era conhecida por ser uma excelente parteira, auxiliando o parto tanto de mulheres negras quanto brancas. Minha prima Pansy me disse que Mãe Liza trouxe centenas de bebês ao mundo e que devido ao seu enorme conhecimento, os médicos brancos da região, muitas vezes, lhe imploravam para ajudá-los em partos difíceis. Podemos dizer que as ações de Mãe Liza ajudaram a estabelecer uma tradição de enfermagem entre as mulheres da minha família. Minha tia Mary e minha irmã Mildred eram enfermeiras e eu também estudei por um tempo para exercer a profissão.

Minha mãe, Mama Freeney, também tinha muitos dos atributos curativos da sua mãe e sua avó. Quando eu era criança, ela mantinha ervas na despensa da cozinha para fazer chás e cataplasmas para nós quando estávamos doentes. Sua despensa era algo semelhante a uma farmácia de ervas, servindo amigos e vizinhos, bem como a família. Ela também usava remédios caseiros, como por exemplo, colocar uma meia com fatias finas de cebola no pé de uma pessoa com febre para baixar a temperatura. Minha mãe e suas irmãs eram crentes convictas no poder da natureza e do espírito para curar e transformar. Quando minha irmã Alma era uma garotinha, ela foi atingida por tuberculose óssea e os médicos disseram à família que a perna de Alma teria que ser amputada. Em vez de ceder às ordens dos médicos, minha mãe e minha tia Mary levaram Alma para casa e entre orações e cataplasmas ela manteve sua perna no lugar.

$\mathrm{Na}$ minha vida atual, tenho afinidade por modalidades de curas naturais, lembrando-me das receitas de chá e remédios caseiros da minha mãe e minha bisavó, aprendendo o máximo que eu poder sobre o dar passe - massagens terapêuticas, acupuntura, toque terapêutico, método Feldenkrais e outras técnicas de cuidados alternativos. Mas, mesmo além das questões 
relacionadas à saúde e bem-estar pessoal, eu tento seguir os exemplos de minha mãe e minhas tias em reconhecer a necessidade de criar um ambiente maior de cura e bem-estar, sobretudo no que diz respeito às relações humanas e às estruturas sociais.

Ao longo dos anos 1980 e início de 1990, meu marido e eu ministramos um curso no Seminário de Teología Iliff chamado, "A cura de pessoas e cura da sociedade.” Nós apresentamos aos nossos alunos o conceito de que o corpo político é, em muitos aspectos, análogo ao corpo humano - intensamente interdependente em todas as suas partes e muito suscetível a estímulos negativos e/ou positivos. Textos de pessoas tão variadas como Joanna Macy, Martin Luther King, Jr., Howard Thurman e Thich Nhat Hanh foram leituras centrais, enfatizando que o Espírito, o Universo, de fato, fornece abundância para todos os seres vivos na terra. Realmente, há o suficiente para todos. O pecado maior é a ganância e ela é tão destrutiva para a sociedade quanto é para o organismo de cada pessoa. Como parte do curso, tínhamos convidados que partilhavam as suas perspectivas e histórias com a classe - ativistas comunitários, filósofos, médicos, cientistas, líderes religiosos e escritores. Nossos alunos sempre foram profundamente estimulados pelas conexões que nossos convidados faziam entre cuidar do bemestar dos indivíduos e criar sociedades mais humanas e solidárias.

Na verdade, nosso trabalho atual, o Projeto Veteranos de Esperança, surge diretamente desta experiência de compartilhar os "testemunhos" e do empenho dos ativistas mais velhos com uma nova geração de pessoas preocupadas com a justiça, cura e transformações sociais não-violentos. Graças a minha mãe, eu sou uma pessoa capaz de reconhecer e apreciar as relações entre saúde individual, generosidade, solidariedade e mudança social — pois a hospitalidade e acolhimento de Mama Freeney eram tão restauradores quanto seus chás e toque.

\section{Vultos}

Histórias de fantasmas eram uma tradição do bosque Geórgia que minha mãe trouxe para Chicago e praticava habilmente. Ao contar essas histórias, ela conseguia assustá-lo tanto que você ficaria com medo de ir sozinho ao banheiro para fazer xixi. Algumas das histórias que contava eram contos populares que ela provavelmente herdou de familiares mais velhos como a Vovó Rye. Mas muitas das histórias de fantasmas da minha mãe eram de sua própria experiência. Como minha irmã Mildred afirma, Mama não estava contando "estórias" ela estava contando "o que realmente aconteceu" — ou seja, o que ela dizia era a verdade. Ela cos- 
tumava contar histórias sobre luzes que se acendiam na casa da família quando ninguém estava lá, ou trazia à memória, com meu pai, a história de um cavalo querido e bem treinado que se ergueu sobre suas patas traseiras e se recusou completamente a atravessar uma ponte assombrada em uma noite sem lua. O fato de que muitas vezes ela tinha testemunhas corroborativas tornava as histórias ainda mais aterrorizantes e, ao mesmo tempo, muito prazerosas.

Mas lembro-me muito pouco dos contos. Tive que pedir aos meus irmãos e outros parentes para juntos me ajudarem a reconstituir as histórias. Eu raramente ouvia as versões completas quando criança. Quando ouvia, elas eram tão convincentes que eu fiz o meu melhor para poder esquecê-las. Eu não era muito boa em ser aterrorizada.

Sensibilidades à parte, essas histórias eram um grande divertimento para a família. Mas elas não eram apenas diversão. Minha mãe contava essas e muitas outras históricas como uma forma de transmitir ensinamentos. Ensinamentos sobre cautela, sobre o discernimento; mas suas histórias eram também uma forma de reconhecer a realidade e presença dos espíritos. Quer chamássemos de fantasmas, entidades, anjos, vultos, presenças, ou ventos, os seres que habitavam as histórias de minha mãe foram, em algum ponto, reais. As histórias nos deram um respeito pelo oculto, pelo desconhecido, e uma apreciação para a transmutabilidade da realidade e da forma.

Conjurar e curar são duas formas de transformação, processos de mudança. Assim como o é a militância. Lembro-me de uma história que Bernice Johnson Reagon tem dito em muitas ocasiões sobre a alquimia de cantar nas reuniões de massa, manifestações e passeatas do Movimento Negro. Bernice, uma música, militante e intelectual extraordinária, descreve a experiência de sair de uma igreja que acolhia os participantes no movimento negro e seguir marchando e cantando pelas ruas do Albany, Geórgia, em direção a lojas ou repartições públicas, que eram os lugares visitados no dia de demonstração. Levantando suas vozes com canções de liberdade, na cadência e espírito da igreja, Bernice e seus colegas manifestantes podiam sentir as canções se expandirem pelo ar e transformar o espaço em torno deles. As músicas transformavam a atmosfera, tornando-se uma barreira quase palpável entre manifestantes e policiais, dando aos manifestantes uma proteção interna que lhes permitia mover-se sem medo.

O trabalho de transformação, alterando os interiores e exteriores de uma situação, é uma longa e venerável tradição na experiência sulista Afro-americana. Ao analisarmos nossa história podemos ver uma enorme flexibilidade entre as pessoas que tiveram de navegar pelas vi- 
cissitudes da vida, sob um sistema segregacionista violento e arbitrário de Jim Crow, e ainda cultivar constantemente um sentimento de dignidade pessoal e mútua.

A música, e particularmente a música sacra da experiência negra, tem sido um recurso alquímico para a luta; uma força conjurada. Como Bernice explicou em sua entrevista para o Projeto Veteranos de Esperança, certamente há algo envolto na experiência do tradicional canto congregacional dos negros que, ao longo do tempo, "faz alguma coisa com a matéria da qual você é feito... Isto realmente conecta você com uma força no universo que o faz diferente. Faz você capaz de se mover com um tipo diferente de acesso. Você está em harmonia com outra coisa, diferente do que as pessoas pensam que você está conectado. E eles não podem te atingir..." 5

Ruby Sales, uma militante e membro da SNCC (Student Nonviolent Coordinating Committee - Comite de Coordenação de Estudantes Não Violento) no Alabama, diz que em seus momentos de terror e angústia mais profundos, ela recorria ao poder do canto negro. "[A] única coisa que me faz lidar com situações difíceis é o que tem sempre me ajudado, as músicas dos negros. Cantando aquelas músicas e ouvindo aquelas vozes... eu canto, Will the Circle Be Unbroken?, Tell me How Did you Feel When You Come Out the Wilderness?... We've Come this Far by Faith..." Recorrendo a estas músicas antigas, Ruby ligava-se a uma tradição arrolada em traumas, muito mais velha do que ela mesma. $\mathrm{Na}$ verdade, ela diz que enquanto cantava, se sentia ligada a sua avó e tudo aquilo que a geração passada tinha testemunhado e sobrevivido. "É nesse momento, por meio da música, que eu sou capaz de sentir algo além do que sou. Me torno parte de uma comunidade. Parte de uma luta..."6

A conexão dinâmica de Ruby com sua avó, por meio da militância e das músicas, é sugestivo do rico e complexo engajamento intergeracional ao qual está imbuída a vida de muitas comunidades afro-americanas. $\mathrm{Na}$ minha família, como na maioria das famílias negras do sul dos Estados Unidos, que eu conheci enquanto crescia, crianças e adultos de várias idades passavam grande parte do tempo juntos. Muitas vezes, pelo menos três gerações viviam em nossa casa, e os jovens tiravam proveito da presença amorosa e dos conselhos e do conhecimento dos avós e outros parentes mais velhos. Por outro lado, os membros mais velhos da nossa fa-

\footnotetext{
5 "Bernice Johnson Reagon: The Singing Warrior," Veterans of Hope Project Pamphlet Series 1, No 1; Denver: VOHP, 2000; p. 12.

6 "Ruby Sales: Standing Against the Wind," Veterans of Hope Project Pamphlet Series 1, No 3; Denver: VOHP, 2000; p. 6-7.
} 
mília podiam contar com a companhia e a vitalidade dos mais jovens e não tinham de se preocupar em ficar sozinho ou abandonados durante os anos finais de suas vidas. As crianças foram ensinadas a respeitar os mais velhos e reconhecer que havia espaços e momentos em que eles não podiam se meter em "coisas de adultos".

Havia também certa formalidade nas relações, enraizada nas tradições sulistas e Africanas. $\mathrm{O}$ respeito era mostrado por meio de formas corteses de se posicionar quando falávamos com estranhos, pessoas da autoridade, e qualquer um em uma faixa etária mais elevada do que a nossa. As mulheres eram sempre "Senhoritas" ou "Senhoras" fulano de tal e os homens eram chamados de "Senhores" (a menos que fossem parentes, pois estes eram chamado tia, tio ou primo). Quando crianças, as nossas respostas complementadas por "senhora" e "senhor" indicava a "boa educação" que tínhamos recebido em casa. Mesmo entre os adultos de idades e status similares, que conheciam um ao outro por muitos anos, havia muitas vezes um tipo de cuidado quase cerimonial na forma como interagiam uns com os outros. Em alguns aspectos, esta cordialidade era como um antídoto para as indignidades que estes homens e mulheres sofreriam regularmente. Mas, de tudo o que eu posso entender, esta prática quase exagerada de deferência e cortesia mútua foi um elemento importante nas relações interpessoais de muitas das comunidades da África Ocidental e Central, da qual a maioria dos negros norteamericanos tem sua origem, e era uma característica comum nas comunidades negras em todas as Américas.

Para aqueles de nós que viveram e trabalharam nas pequenas cidades rurais do Sul, durante o movimento negro, estas dinâmicas relacionais tornaram-se parte integrante do modelo de militância que desenvolvemos. Gwendolyn Zoharah Simmons, líder do projeto SNCC em Laurel, Mississippi em 1964, descreve como ela e seus jovens colegas no Verão da Liberdade interagiram com membros mais velhos de comunidades com os quais eles estavam se mobilizando pela reforma política e educacional na região. Zoharah diz:

Nós éramos vistos como 'líderes', pessoas que trouxeram uma visão, pessoas que trouxeram recursos, ideias, materiais que eles queriam. Livros e panfletos e tudo isso. Ao mesmo tempo, devido à nossa idade, éramos vistos como crianças para eles...

7 “Gwendolyn Zoharah Simmons: Following the Call," Veterans of Hope Project Pamphlet Series 1, No 4; Denver: VOHP, 2000; p. 13. 
Vivendo com líderes comunitários locais, esperava-se de Zoharah, e de outros jovens militantes, a reprodução das honrosas formas afro-americanas de relações intergeracionais. A senhora Euberta Sphinx, uma ativista de longa data na comunidade Laurel, abriu as portas de sua casa e de seu coração para Zoharah. De modo geral, a relação que as duas mulheres desenvolveram era indicativa da forma como os militantes mais jovens e os cidadãos mais velhos colaboravam uns com os outros:

Eu tinha que obedecer a senhora Sphinx, quando se tratava de qual hora eu deveria chegar e para onde eu estava indo. Eu tive que dizer a ela onde eu estava indo e onde eu tinha ido. Se ela dissesse que eu tinha de ir à igreja, eu tinha que ir. Mas, ao mesmo tempo, eles estavam dispostos a me seguirem para dentro das mandíbulas da cadeia... Era uma dinâmica muito interessante ${ }^{8}$.

Esta "dinâmica interessante", com raízes na família e nas tradições culturais dos afroamericanos do sul dos Estados Unidos, era um elemento central na estratégia de organização do movimento negro e a razão para a ressonância e sucesso do movimento em toda a região. Embora, provavelmente houvesse momentos em que os jovens da SNCC, CORE (Congress of Racial Equality - Congresso de Igualdade Racial) e outras organizações do movimento negro se sentiam constrangidos com as expectativas de comportamento dos mais velhos, essas normas de comportamento foram medidas práticas que asseguravam o bem-estar dos jovens, os quais (mesmo que fossem sulistas de nascimento) muitas vezes estavam desfamiliarizados com a comunidade local para onde foram designados. Os jovens militantes foram extremamente agraciados por estarem integrados às estruturas e conexões das famílias e da igreja. "Obedecer" aos mais velhos foi uma forma de demonstrar respeito e reconhecimento pela liderança organica e autoridade da comunidade popular. Além disso, a proximidade e familiaridade criada por relações inspiradas nas interações familiares, foram importantes fontes de conforto, estabilidade e suporte em meio a tensões extremas, incertezas e violência terrorista que eram ameaças constantes para todos nas comunidades negras do interior do sul norteamericano.

Este modelo de mobilização indígena Afro-americano reflete muitos elementos da orientação religiosa e cultural que aprendi quando criança. Aqueles que abriram suas casas, suas igrejas e suas lutas para os jovens trabalhadores para libertação negra demonstraram uma forma de hospitalidade e de grande generosidade de espírito que conheci pela minha própria experiência de família. As relações entre jovens ativistas e membros mais velhos da comuni-

8 Ibid. 
dade local me traz à memória os modos pelos quais os meus irmãos, meus primos mais novos e eu interagíamos com as pessoas idosas em nossa família e vizinhança. Por fim, foi a difusão do Espírito, o poder curativo e transformativo dos recursos culturais e religiosas de nosso povo, e um reconhecimento da presença de Deus mesmo nos momentos mais perigosos, que sustentou o movimento negro - como ainda mantém muitos de nós ainda hoje em nossa jornada.

\section{Referências}

"Bernice Johnson Reagon: The Singing Warrior," Veterans of Hope Project Pamphlet Series 1, No. 1. Denver: Veterans of Hope Project, 2000.

FULOP, Timothy and RABOTEAU, Albert J. African American Religion: Interpretive Essays in History and Culture. New York: Routledge, 1997.

"Gwendolyn Zoharah Simmons: Following the Call," Veterans of Hope Project Pamphlet Series 1, No. 4. Denver: Veterans of Hope Project, 2000.

LONG, Charles. Significations: Signs, Symbols and Images in the Interpretation of Religion. Philadelphia: Fortress, 1986.

"Ruby Sales: Standing Against the Wind," Veterans of Hope Project Pamphlet Series 1, No 3. Denver: Veterans of Hope Project, 2000.

Recebido em 15 de agosto de 2015.

Aceito em 19 de setembro de 2015. 